\title{
Arthur Holmes' paper of 1929 on convection currents within the Earth as a cause of continental drift
}

\author{
School of History and Philosophy, The University of New South Wales, NSW 2052, Australia. E-mail: d.oldroyd@unsw.edu.au
}

\section{Arthur Holmes (1890-1965)}

Holmes is widely regarded as one of the finest geologists of the twentieth century and probably the greatest British geologist of his day. He was professor first at the Durham University and then at Edinburgh, where he is still revered. He did substantial work in Africa and Burma and made contributions in petrology, geomorphology, geophysics, structural geology and geochronology. His knowledge of the geological literature and world geology was comprehensive. Holmes was also the author of an extremely successful geology textbook (Holmes, 1944 and 1964). But perhaps his most important work involved the study of radioactive materials as a pioneering means of assessing the age of the Earth, arriving at a figure in excess of a billion years, and his arguments in favour of convection currents within the Earth as a cause of 'continental drift'. Thus he gave the first reasonably plausible and comprehensive physical mechanism to explain the 'drift' hypothesised by Alfred Wegener to account for the extensive empirical evidence for the occurrence of relative lateral movements of the Earth's crust. The paper in which he published his evidence and reasoning on this topic (Holmes, 1929) is the subject of the present contribution to the 'Classic Papers' series. A good introductory account of Holmes' life and work is provided by Lewis (2000). A valuable paper on the early development of Holmes's ideas about subterranean convection currents and their tectonic consequences is to be found in Frankel (1978).

\section{The paper}

The paper discussed here was first presented as a lecture to the Glasgow Geological Society on 12 January 1928. It was published that year in summary form in Geological Magazine (Holmes, 1928), and in full in the Transactions of the Geological Society of Glasgow in 1929 (Holmes, 1929) though the printing of the issue was late and it actually appeared only in 1931.

\section{Background}

As is well known, Alfred Wegener proposed his famous theory of continental drift in 1912 (partial English translation, Fritscher, 2002), and in book form three years later (Wegener, 1915). It attracted considerable interest as it accounted for many curious geological features but people were sceptical at first, as Wegener was unable to offer any plausible physical hypothesis as to why the continents might move as they seemingly had done. How could continental masses plough through the Earth's crust like ships at sea? Wegener's suggestions, such as the idea of 'pole-flight' due to the Earth's rotation, were obviously insufficient to account for the 'drift' of continents. On the other hand, seismic evidence (e.g. Oldham, 1906) suggested that some - in fact much — of the Earth's interior was fluid.

At the time of Holmes's Glasgow paper the tide of opinion was definitely running against Wegener's theory, as shown most clearly in the proceedings of a conference organised by the American Association of Petroleum Geologists in New York in 1926 (van Waterschoot van der Gracht, 1928), where the majority of participants spoke against the drift hypothesis. However, there was some support for 'mobilism' and some relevant general theories of the Earth were on offer and deployed by Holmes. In particular, he embraced the theories of geosynclines and isostasy; and ideas about the internal heat of the earth due to radio-thermal energy having tectonic effects, envisaged by the Irish physicist and geologist John Joly (1857-1933), were also utilized, as were some suggestions by the respected amateur geologist Alfred Joseph Bull (1875-1950) concerning convection currents within the Earth's hot interior. In fact, Bull (1921, p. 364) wrote: "It is here suggested that the folding of mountain ranges may be produced by the frictional drag of moving portions of the asthenosphere, and that these movements may be convective and result from its unequal heating by radio-active elements". There is no doubt that Holmes picked up this idea from Bull as he specifically referred to it in his 1928 paper. However, Bull's suggestion was that the convection currents arose from the irregular distribution of subterranean radioactive elements; and he did not choose to try to develop the idea or its implications much further.

Joly and Holmes were both pioneers in the investigation of the role of radiogenic heat in the Earth's history and, as mentioned, Holmes' early investigations of the age of the Earth were of great importance. Joly (1910) suggested that the emission of heat from radioactive substances accumulated in geosynclines could lead to episodic eruptions of plateau basalts and orogenies. Subsequently (Joly, 1924, 1925) argued that the Earth could not be cooling as Lord Kelvin had supposed in the nineteenth century. On the contrary, it was constantly generating subterranean heat, which was discharged from time to time. The heat generated below the heat-blanketing continental areas of the crust could not readily escape but this would be possible if the sub-continental basic materials moved into the oceanic regions. Joly suggested that this could happen because of differential tidal movements between the solid crust at the more fluid hot substratum, there being, he thought, a westerly tidal drift of the 
whole crust over the hotter and more fluid substratum. (The whole of the Earth spins towards the east, but the fluid substratum moves more freely. So the solid continental crust lags behind the fluid substratum. Thus in effect there is a westerly tidal drift of the solid crust.) This, suggested Joly, permitted the release of pent-up radiogenic heat, as the overlying sialic continental slabs (which impeded the escape of heat) moved to different positions relative to the underlying basic crustal rock, until such time as the more fluid material had lost heat and hardened.

Holmes was fully familiar with the work on radiogenic heat, and he agreed that some process for the release of the heat generated at depths was needed, but Joly's suggestion was, he thought, implausible.
It was the search for a heat release mechanism that led Holmes to entertain the idea of some kind of convection process being responsible, which would at the same time offer a mechanism for the processes envisaged in Wegener's theory of drift. However, as he pointed out, he was not the first to contemplate some kinds of convection currents within the Earth.

What follows is the text of parts of Holmes' paper of 1929, with summaries of the sections that have been omitted. His paper is historically important if for no other reason than that it offered the first diagram that represented a convective process to provide an explanation of drift. The paper's original pagination is indicated in parentheses, but his references are mostly omitted.

\title{
Radioactivity and Earth Movements [p. 559]
}

\author{
Arthur Holmes \\ I.- TECTONIC HYPOTHESES.
}

[Holmes' paper begins by listing the types of forces to which the Earth is subject.] $\ldots$

[p. 560]

Gravitational:

Cosmic Stresses set up by

(a) Tides due to the sun and moon

(b) Precession of the equinoxes.

Terrestrial

(c) Attraction between continents

(d) Pohlflucht force

Stresses set up by

(e) Departures from isostatic equilibrium

(f) Departures from hydrostatic pressure in the crust

(g) Condensation due to re-adjustments of the material of the earth

Thermal:

Stresses set up by

(h) Contraction due to change of state and cooling by conduction

(i) Expansion due to heating-up of the earth's interior

(j) Contraction ( $h$ ) and expansion (i) alternating in time (Joly's hypothesis of thermal cycles)

( $k$ ) Convection currents in the substratum (the hypothesis developed in this paper).

[He concludes that none of the gravitational forces and stresses are adequate to account for the phenomena discussed in Wegener's drift theory. But 'thermal processes' warrant further consideration].

[p. 563] This introduces us to the suite of hypotheses in which thermal processes play the leading part. The earlier attempts, antedating the discovery of radioactivity, need not be discussed. Those developed since are of four chief kinds; they may all be tested by comparing their consequences with the geological behaviour of the earth's crust.

(h) In 1915 I adopted the traditional hypothesis of a steadily cooling earth, and assumed that the effects of radioactivity were limited to slowing down the rate of cooling. Instead of calculating the age of the earth from the present thermal state of the crust, as [Lord] Kelvin had done, I took the age as a known datum and assumed that radioactivity fell away exponentially with depth, so that the present average gradient could be reached after 1,600 million years of cooling. With a known distribution of radioactivity, it was then possible to calculate the present downward variation of temperature. ...

The consequences of this hypothesis (which reconciles all the more obvious thermal data quite satisfactorily) have been very thoroughly explored by [Harold]Jeffreys. In 1925, however, I abandoned the hypothesis because of its failure to account for the leading phenomena of geological history [Holmes, 1925a, 1925b]. The objections are:

(1) Its inconsistency with the prevalence of vulcanism of the plateaubasalt type....

(2) Its quantitative inadequacy to provide the contraction necessary to produce folded and overthrust mountain structures. The calculated reduction of area is only about one sixth of the amount calling for explanation. 
(3) The distribution of orogenic periods in time is systematically different from that deduced from the hypothesis. By admitting deep-seated cooling by convection, Jeffreys now provides more nearly uniform intervals between successive orogenic periods, but only at the expense of discrepancy which becomes still greater.

(4) The improbability that compression dispersed through [p. 564] a layer $150 \mathrm{~km}$. thick could produce relatively superficial nappe structures like those of the Alps.

(5) The failure of the hypothesis to account for marine transgressions, and particularly for the development of geosynclines.

(6) The fact that under the hypothesis continental drift is manifestly impossible. It is of no service to say, as Jeffreys does, that continental drift is "out of the question."

(7) No geochemical reasons are offered for the fundamental supposition that the substratum is so poor in the radioactive elements that its heat output can be ignored.

(i) In the remaining hypotheses this unnatural limitation of radioactivity to the crust is rejected. The geochemical and physical evidence, as we shall see, is certainly in favour of a slightly radioactive substratum and this implies the production of an excess of heat over and above that conducted to the surface. In flat contradiction to the contraction hypothesis, [Bernhard] Lindemann considers the earth to be expanding as a result of the continuous internal accumulation of radio-thermal energy. However, this idea is geologically untenable. Many processes would intervene to permit the escape of excess heat and cumulative expansion would not occur so long as these continued to operate. ...

(j) In Joly's well-known hypothesis of thermal cycles an alternating accumulation and discharge of heat is visualised. Accumulation leads to fusion of the substratum (regarded as of basaltic composition); crustal extension; volcanic activity; and marine transgressions. Westerly tidal drift of the crust slowly draws the ocean floors over the magma zone, and discharge of heat is brought about by thinning of the oceanic crust. Solidification sets in by crystallisation and the sinking of blocks, accompanied by crustal compression and marine recessions.

As the period of Joly's cycles seemed to be inconsistent with the duration of geological time as estimated from lead-ratios, I suggested in 1925 the possibility of longer periods referred to similar cycles arising in a substratum of peridotitic composition, [p. 565] the radioactivity of which was regarded as being much less than that of the "basaltic" layer above it. This conception has been further developed by [L.J.] Krige with special reference to the currents which would be set up between the hotter sub-continental and the cooler sub-oceanic regions. These modifications of Joly's original scheme do not, however, remove the physical difficulties in the way of its acceptance.

[But] Joly has boldly faced the situation that arises if an excess of heat is generated in the substratum, and he has clearly realised that some form of crustal drift is absolutely necessary to permit the discharge of such heat.

( $k$ ) From the above discussion it will be realised that the substratum should still be in a "fluid" or glassy state. One of the objects of this paper is to discuss a mechanism for discharging the excess heat, involving circulation of the material of the substratum by convection currents, and continental drift operated by such currents. Tidal friction may co-operate to a slight extent, but is not essential. The possibility that currents might be set up by differential radioactive heating was recognised by [Alfred]Bull in 1921, though in 1927 he considered that little evidence could be adduced in its support. [Otto] Ampferer has postulated unterströmungen in the substratum to explain crustal [p. 566] movements, and [Robert] Schwinner considers the currents to be due to convection. [Ernst] Kraus also finds it necessary to adopt magmatic currents to explain the evolution of geosynclines, orogenic belts and continents. [?] Born has pointed out that, although such hypotheses thoroughly meet the geological requirements, they suffer from the defects that they demand extensive movements in the substratum and require a source of energy that has not been made intelligible. But one need not look far for an adequate source of energy. It is to be found in the radioactive elements. $\cdots$

\section{II.- THE NATURE OF THE CRUST AND SUBSTRATUM.}

In recent years the comparative study of the seismograms of near earthquakes has thrown new light on the structure of the continental crust. The recognition of the $P_{g}, P^{*}$ and $P$ waves ${ }^{1}$ and the corresponding $S$ waves indicates that three distinct layers, known respectively as upper, intermediate and lower, are concerned in their propagation....

[p. 567]

. .

The Upper Layer has been generally identified with granite, but petrological evidence indicates that the range of rocks of the sial suite is from granite to diorite, and that granodiorite is nearer the average composition than granite. Moreover, the properties of the layer are complicated by the presence of a sedimentary and schistose cover of very variable thickness, and by widely distributed intrusions of basic rocks....

The thickness of the upper layer is found by Jeffreys to be about $10 \mathrm{~km}$. in the neighbourhood of Great Britain and the [p. 568] adjoining parts of Europe, rising to $12 \mathrm{~km}$. when the Alpine region is included. [Beno] Gutenberg and the Japanese seismologists find rather higher values.

The Intermediate Layer has given rise to much discussion. Jeffreys cautiously favours an identification with tachylyte (glassy basalt), but this is unacceptable on geological grounds. I suggested diorite or quartz-diorite as a more reasonable alternative. ...

Diorites and quartz-diorites are likely to be

(a) differentiation products of granodioritic magmas;

(b) products of reaction between granitic magmas and sediments in the hearts of mountain systems; or

(c) hybrid rocks due to interaction between basaltic magmas and granitic rocks or magmas.

They are essentially sialic rocks, and if we admit their presence in the upper layer, as we must, there is no longer any reason to postulate their abundance in the intermediate layer. As a working

\footnotetext{
${ }^{1}$ These symbols referred to P-waves. $\mathrm{P}_{\mathrm{g}}$ denotes P-waves that travel through the upper granitic (sialic) layer of the Earth's crust, coming from a seismic source to the point of recording. $\mathrm{P}^{*}$ denotes waves coming from seismic source close to the 'Conrad Discontinuity' between the upper granitic and lower basaltic layers of the crust. $\mathrm{P}$ denotes a wave propagated for part of its travel-time in the mantle below the Moho Discontinuity and is normally denoted by $\mathrm{P}^{\mathrm{n}}$.
} 
hypothesis the latter will here be regarded as amphibolite, probably passing downwards into granulite, both facies being subject to local transformation into eclogite under appropriate dynamic conditions.

The thickness of the intermediate layer is found by Jeffreys to range from 20 to $25 \mathrm{~km}$. Other observers confirm these figures or favour a slightly greater thickness.

The Lower Layer may be eclogite or some form of peridotite, identifications that are supported by [Percy]Wagner's discussion of the kimberlite xenoliths. Geochemical and petrological evidence and the analogy with meteorites suggest that the lower layer is most likely to be of peridotitic composition, while the thermal evidence favours the view that the material is in a glassy rather than a crystalline state....

The term crust is used for the upper and intermediate layers and any part of the lower layer that is crystalline, while the term substratum is adopted for the underlying thermally "fluid" or glassy part of the lower layer.

Turning now to the oceanic part of the crust, we have little information except that its properties are consistent with its identification as gabbro or amphibolite. . . The thickness of the oceanic crust is probably of the same order as that of the continents; thermal considerations suggest that the former is likely to be thicker than the latter. The lower layer of the oceanic areas cannot be distinguished from that lying beneath the continents. The substratum thus appears to be a continuous shell bounded above by the crust and below by the metallic core. The core extends from 2,900 km. to the centre and its nature is reasonably well established by many converging lines of evidence.

\section{III.- THE RADIO-THERMAL ENERGY GENERATED IN ROCKS.}

Since Kelvin's method of dealing with the problem of the earth's thermal history was shown to be invalid by Lord Rayleigh's discovery of the widespread distribution of the radioactive elements in rocks, various attempts have been made to tackle the problem afresh. Although numerically the actual proportions of the radio-elements (other than potassium) are exceedingly small, yet owing to the fact that their disintegration is accompanied by the liberation of heat, their presence is of an importance that cannot be overemphasized. The total annual heat outputs are as follow:

[p. 571]

$\begin{array}{ll}\text { Uranium family } & 7,900 \times 10^{-4} \text { cals./gm. U. } \\ \text { Thorium family } & 2,300 \times 10^{-4} \text { cals./gm. Th. } \\ \text { Potassium } & 1.24 \times 10^{-4} \text { cals. } / g m . K . \\ \text { Rubidium } & 2.38 \times 10^{-4} \text { cals. } / g m . R b .\end{array}$

The geothermal effects of potassium are of the same order as those of the more strongly radioactive families, because of the great abundance of potassium in rocks. The output from rubidium, however, can be ignored because of the rarity of this element.

[T]o ignore the ceaseless outpouring of energy that is everywhere occurring in terrestrial materials would be as wrong as to ignore the effects of gravitation.

\section{IV.- THE DECREASE OF RADIOACTIVITY WITH DEPTH.}

We must next compare the heat-output of the rocks with that lost from the continents by conduction to the surface and radiation into space. The average amount of heat so lost from each sq. cm. per second is given by the product of the average thermal conductivity of rocks (0.006) and the average temperature gradient $\left(0.00032^{\circ} \mathrm{C}\right.$. per $\mathrm{cm}$.). The loss per year $\left(3.15 \times 10^{7}\right.$ secs. $)$ is therefore $0.006 \times$ $0.00032 \times 3.15 \times 10^{7}=60$ calories $/ \mathrm{sq} . \mathrm{cm}$. Evidently this could be made good by the radio-thermal energy generated within a thickness of $14 \mathrm{~km}$. of granite; $16.5 \mathrm{~km}$. of granodiorite; $52 \mathrm{~km}$. of plateau basalt or gabbro; or $60 \mathrm{~km}$. of peridotite. It may therefore be inferred that the earth's radioactivity is strongly concentrated towards the surface.

[p. 573] The facts of distribution and the geochemical behaviour of the elements in question are definitely in accord with this inference. However we ... combine the thermal data on $p .571$ with the seismic and petrological evidence bearing on the structure of the crust it seems certain that an outer shell of the earth less than $60 \mathrm{~km}$. thick must generate sufficient heat to make good the loss from the surface. The distribution of radioactivity favoured by Jeffreys, and limited to allow the interior of the earth to cool, corresponds with a layer of granite $11 \mathrm{~km}$. thick underlain by a basaltic layer $22 \mathrm{~km}$. thick. There is then no excess of radioactivity left over for the interior. The temperatures of the basaltic layer are about $300^{\circ} \mathrm{C}$. at the top and $650^{\circ} \mathrm{C}$. at the base. Clearly these are too low to permit vulcanism of the plateau-basalt type. If basalt magma comes from a greater depth, the distribution of radioactivity necessarily involves the production of an excess of heat, and igneous activity becomes the mechanism by which part of the excess is enabled to escape. But in this case the original restrictions imposed by the hypothesis of limited radioactivity have been fatally exceeded. The substratum becomes permanently "fluid" in the thermal sense and the earth cannot cool down in the manner postulated.

Jeffreys [1929] has shown that if the limited amounts of the radioelements admitted to be present in the crust were uniformly distributed through the 2,900 km. shell, then the material below a depth of some $50 \mathrm{~km}$. could never have solidified. Convection would then proceed in the substratum until the radio-elements became strongly concentrated towards the surface. He writes, "the transfer would only stop when the temperature gradient at all depths had become so low as to permit solidification. This implies that the concentration would ultimately be almost complete". I can see no reason for supposing that the freeing of the substratum from the radio-elements can yet have become as complete as Jeffreys requires. All the experience of geochemistry is strongly opposed to such a hypothetical possibility. No process of magmatic differentiation is known that could bring it about. It is likely that the material of the upper layer, together with the oceans and the atmosphere, was differentiated from the general body of the earth while the latter was still a relatively mobile fluid. The process of "gaseous transfer" so implied would be very effective in leading to a marked [p. 574] concentration of the radioelements in the first-formed crust. But the known radioactivity of basalts and peridotites of widely different ages shows that the suggested process was far from removing all the radio-elements from the substratum. Yet clearly, if we admit only a slight radioactivity in the substratum there must be generated within it an excess of heat which would maintain fluidity.

Let us suppose, to illustrate the effects of slight radioactivity, that the heat output within the substratum is only 1/700 of that of plateau basalt. On geochemical grounds it is difficult to see how this can be anything but an underestimate. The volume of the substratum $(60 \mathrm{~km}$. to 2,900 km.) is $88.75 \times 1,010 \mathrm{cu}$. km., and the total heat 
generated per year on the assumed figure is $142.5 \times 1,017$ calories. This is equivalent to the cooling of $62 \mathrm{cu}$. $\mathrm{km}$. of basaltic magma from $1,000^{\circ} \mathrm{C}$. to a crystalline rock at $300^{\circ} \mathrm{C}$. Obviously, to get rid of this quantity of heat some process much more drastic than ordinary volcanic activity would be called for. The volume of lava in the 1929 eruption of Vesuvius was only $12 \times 103 \mathrm{cu}$. $\mathrm{km}$. The annual loss of heat from all volcanic sources has been estimated at $6 \times 1,017$ calories.

For the accumulated heat of 200 million years to escape through the sites of the oceans it would be necessary for one third of the whole of the ocean floors (taken at $60 \mathrm{~km}$. thick) to be engulfed and heated up to $1,000^{\circ} \mathrm{C}$., and replaced by magma which cooled down to form new ocean floors at $300^{\circ} \mathrm{C}$. A process competent to bring about this result on the scale indicated would be some form of continental drift involving the sinking of old ocean floors in front of the advancing continents and the formation of new ocean floors behind them.

We may therefore conclude that

(a) if the crust of the earth makes good the loss of heat by conduction to the surface, and

(b) if the substratum has only 1/700 of the heat-generating capacity of plateau basalt; then

(c) the substratum cannot yet have cooled sufficiently to have crystallised, but must still be in the stage of convective circulation, and

(d) to avoid permanent heating-up, some process such as continental drift is necessary to make possible the discharge of heat.

\section{[p. 575] V.- CONVECTION CURRENTS IN THE SUBSTRATUM.}

\section{THE CONDITIONS FOR CONVECTIVE CIRCULATION.}

In the simple case of an extensive layer of uniformly heated viscous liquid, with rigid conducting surfaces above and below, the conditions leading to convection currents are fairly well understood. There is stability until a certain critical temperature gradient is reached, depending upon the compressibility, conductivity, and viscosity of the fluid. As the critical gradient is exceeded, the uniformly stratified distribution of material becomes unstable, and in the attempt to restore stability a system of complementary currents begins to develop, ascending in some places and descending in others. The disturbances are at first chaotic, but of all the possible systems of movement some tend to persist and to increase steadily with time at the expense of others. This leads gradually to the survival of local centres from which vertical currents ascend. Towards the top the currents spread out in all directions from each centre until they interfere with one another, turn downwards, and form sheet-like return currents. Thus irregular polygonal prisms come to be enclosed by the downward currents. Under ideally uniform conditions the polygons would ultimately become hexagonal and the diameter of the hexagons would be three or four times the depth of the convective layer.

In the earth the critical gradient appears to be about $3^{\circ} \mathrm{C}$. per $\mathrm{km}$. So long as this is exceeded convection must go on, provided that the material has no strength, and that the viscosity is not too high.

...

At high temperatures the strength of materials rapidly diminishes and, as the fusion point is approached, it disappears. It is therefore to be expected that the substratum should be devoid of strength. Geologically, the abundant evidence pointing to regional isostatic compensation within a depth of $60 \mathrm{~km}$. or less is the best indication that this expectation is realised.

...

In further support of the inference that the substratum has no strength we can appeal to the secular variation of the earth's magnetism, which, as already pointed out, implies relative mobility of the interior. The only theory which provides for the maintenance of the earth's magnetism, and which is not contradicted by other observed facts, has been proposed by [Joseph] Larmor; it involves the circulation of the material within the earth by a system of currents symmetrical about the axis and the magnetic equator.

Granting the physical possibility of convection within the substratum, the effect of radioactivity would be to steepen the gradient over the critical gradient and so increase the rate of circulation until the new heat could be carried off as fast as [p. 577] it was generated. With the differentiation and crystallisation of the crustal materials, the interior would be able to discharge the excess heat only in so far as the crust could be fused or broken through from below. Both processes are described in the sections that follow.

... [The circulation]will depend mainly

(a) on the varying thickness of the substratum from equator to poles;

(b) on the varying thickness and radioactive content of the crustal cover; and

(c) on the rotation of the earth; upward moving currents will be deflected westwards and downward currents eastwards; in the northern hemisphere horizontal movements will turn towards the right and in the southern towards the left; such deflections, however, are likely to be very slight, and they will not be further discussed at present.

\section{THE PLANETARY CIRCULATION.}

Considering the first of these we may infer by analogy with the atmosphere a circulation like that of the planetary system of winds. Within the earth the ellipticity of successive shells of increasing density gradually decreases with depth. Thus a considerable part of the difference between the polar and equatorial radii will be concentrated in the substratum. The equatorial thickness being greater than that beneath the poles, and the distribution of radioactivity being independent of latitude, the equatorial temperature gradient will be steeper than that towards the poles. Thus the general circulation from this cause should be as shown in Fig. 1.

As the equatorial ascending currents approach the base of the crust, they divide; half turning north and half south. As a result of

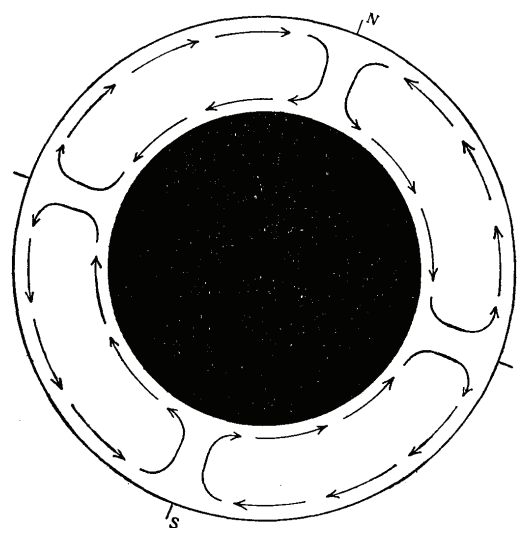

Figure 1. 
the powerful drag thus imposed on the lower part of the crust the latter will flow with the currents but with a lower velocity, each level moving less rapidly than its underlying neighbour. The upper levels will tend to give way by fissuring or faulting as in the case of a glacier or ice-sheet. Thus the ultimate effect on continental blocks originally over the equator will be to drag them apart, leaving a depressed geosynclinal or oceanic belt along the equator. ... [p. 578] The long history of the Tethys girdling the continental half of the earth between Gondwanaland and Laurasia is a clear indication of the operation of some opposing force tending to pull the continents apart. In the planetary circulation we have a first clue to its nature. The closing up of the Tethys is referred to the subsequent action of the sub-continental circulations.

\section{THE SUB-CONTINENTAL CIRCULATION.}

Superimposed upon the general planetary circulation there must be cyclonic and anticyclonic systems set up by the effects of regions of greater and less radioactivity in the overlying crust. Chief of these are the monsoon-like currents due to the distribution of continental blocks and ocean floors. Such evidence as we have, suggests that the radioactivity of continental rocks is [p. 579] generally greater than that of oceanic rocks. Thus, although the temperature at the base of the crust will be everywhere nearly the same, the continental crust should be thinner than the old or normal oceanic crust, and thus beneath the continents the temperature should be higher than at the same level beneath the oceans. The circulation due to this unequal heating of the substratum would be a system of ascending currents somewhere within a continental region, spreading out at the top in all directions towards the cooler peripheral regions. The downward currents would become strongest beyond the continental edges where weaker currents from the oceanic regions would be encountered (Fig. 2). ${ }^{2}$

In the simplest case the drag on the base of the continental crust would be radially outwards, but in reality the circulation would necessarily be more complex. Ascending currents would not generally be localised about a single centre, but rather about several centres and along previously thickened belts such as those of mountain ranges. In the peripheral regions, however, the currents would be everywhere directed towards the oceans.

In Fig. 3 an attempt has been made to represent the effects on a continental profile under ideally simple conditions. Where the
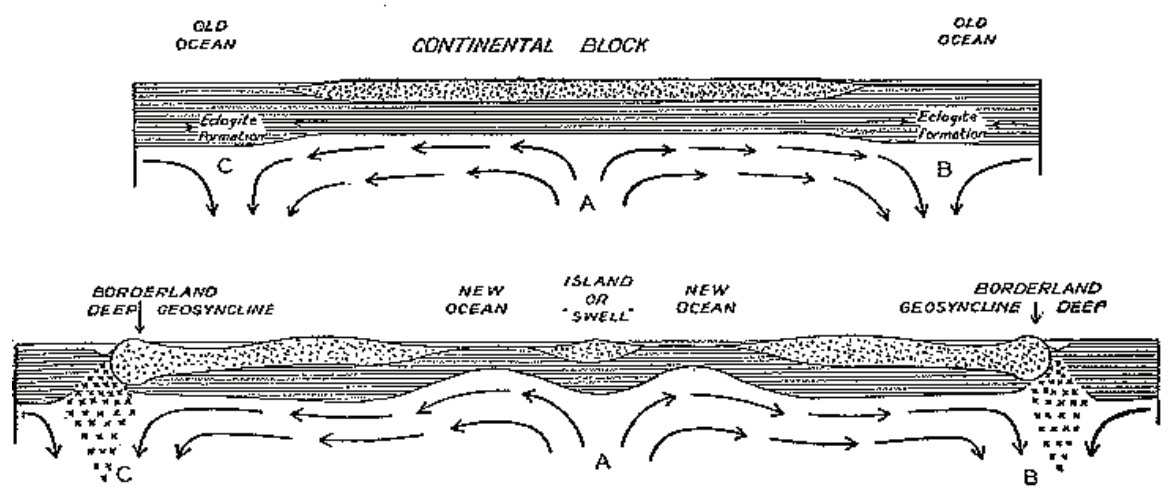

Figures 2 and 3. ascending currents turn over, the opposing shears and the resulting flowage in the crust would produce a stretched region or a disruptive basin which would subside between the main blocks. If the latter could be carried apart on the backs of the currents, the intervening geosyncline would develop into a new oceanic region. The formation of a new ocean floor would involve the discharge of a great deal of excess heat. It will be [p. 580] shown later that the new crust will be more nearly basaltic in composition and more richly radioactive than the normal material of the substratum,

We must next consider what will happen at the continental margins, or generally, where two currents meet and turn downwards. The crust above the zone of contact will be thrown into powerful compression and the amphibolite layer will tend to be thickened by accumulation of material flowing in from two directions. The observed effects of dynamic metamorphism at high temperature and differential pressure on such material lead us to expect that recrystallisation into the high-pressure facies, eclogite, will here take place on a large scale. The change of density from 2.9 or 3.0 to 3.4 or more, combined with the simultaneous operation of isostasy would lead to marked subsidence. ... Such foundering would effectually speed up the downward current for two reasons: the greater density of the sinking blocks, and the cooling of the substratum material in their vicinity.

... [E]clogite formation . . provides a mechanism for "engineering" continental drift, and at the same time for discharging some of the excess heat generated in the substratum. Each part of the continental block would be enabled to move forward, partly by the fracturing and foundering of the belt of ocean floor weighed down with eclogite immediately in front, and partly by over-riding the ocean floor along thrust planes lubricated by magmatic injections from below.

The hypothesis of eclogite formation is supported by the fact that it provides a reasonable explanation of oceanic deeps. It is consistent with their depths, as judged from the requirements of isostasy, and with their occurrence in front of the active orogenic arcs bordering the Pacific on the Asiatic and Austral-asiatic side. That oceanic deeps are under compression is the opinion of [Felix Vening] Meinesz. ${ }^{3} \mathrm{He}$ sees in downward flexure under stress a reason for the local defects of gravity revealed over deeps by his gravity surveys of the oceans. .

\section{[p. 581]}

The upper or sialic layer of the continental margin will also be thickened by the differential flowage of its levels towards the obstructing ocean floor. Here thickening of the crust and mountain building will occur, and the mountain roots, unable to sink, will begin to fuse and give rise to igneous activity of the CircumPacific type with basalt-andesite-rhyolite volcanoes. It has frequently been pointed out that, if the material of the ocean floor is weaker than that of the advancing continent, then mountain building will not take place; while if it is stronger, continental advance becomes impossible. With the mechanism here suggested this impasse does not arise. Mountain building occurs as a result of rock-flowage set in

\footnotetext{
${ }^{2}$ The words above $C$ and $B$ in the upper figure (Fig. 2) are ECLOGITE FORMATION. The clusters of crosses near $C$ and $B$ in Fig. 3 are intended to denote descending blocks of eclogite. (See the following paragraph.)

${ }^{3}$ See Vening Meinesz (1930). Holmes could have known about this publication as his paper was actually published well after its presentation.
} 
operation by the underlying current; it will generally occur provided that the horizontal component of flowage is greater from behind than in front. Deep-seated outflow of sial beyond its former margin appears to be involved in the great and geologically rapid uplifts indicated by the presence of abyssal deposits in the outer sedimentary zone of many island arcs. The forelands move like an ice-sheet, the upper levels being carried forward as a dead weight devoid of orogenic energy other than that which is derived from the active substratum below.

The effects of possible fusion and of differential flowage of the amphibolite layer remain to be considered. Since the outward transport of heat towards the periphery along any stream-line from the area where the currents ascend necessarily increases with the distance from that area, the currents will begin to fuse the base of the crystalline crust and a process of magmatic corrosion and transport will develop. This will become cumulative towards the periphery. At first the material undergoing fusion is likely to be peridotite, but sooner or later a point will be reached where partial fusion of amphibolite will occur. At the same time the lower layers of the amphibolite will be carried forward by rock-flowage more rapidly than those at higher levels. In part, the spilitic or basaltic magmas so generated may give rise to vulcanism above, but most of the magma should escape into the zone where the flowing amphibolite is being transformed into eclogite. There the magma will facilitate sinking of the eclogite blocks and lubricate the shear planes over which the continent advances. The place of the material removed [p. 582] from the amphibolite layer will be taken by the heavier material of the substratum, and, in accordance with isostasy, the region above will subside; that is to say it will become a geosyncline. By the accumulation of sediments from the continent behind and the borderland or mountain arc in front, further subsidence of the geosyncline will occur. Thus the base of the crust will be kept hot, and may even grow hotter, and the process of geosyncline development will continue. It should be noticed that this region, though tending to subside, will nevertheless be under compression whenever rock-flowage in the underlying sial is more rapid than that in front. Thus folding may proceed concomitantly with subsidence and accumulation of sediments. This is well known to have occurred, but hitherto no explanation has been offered. Such geosynclines will be referred to as interior geosynclines. Those within the Asiatic island festoons are active examples. Compression associated with depression has been proved by recent geodetic measurements in the Kwansai District of Japan.

Sooner or later a time will come when the buried crustal material beneath the infilled geosyncline will become hotter and weaker than the material behind and in front. Moreover, the grip of the underlying current will have weakened as a result of the higher temperature and lowered viscosity. At this stage thickening of the geosynclinal belt due to compression will become more effective than thinning by magmatic corrosion; mountain building will have set in (Fig. 4). ...

[p. 583] Meanwhile the mountain roots will set up an accelerated transport of heat towards the continental edge, and the currents will thus move out far beyond the edge before beginning to descend. The

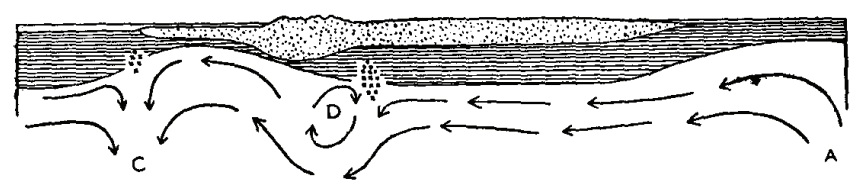

Figure 4. borderland or mountain arc will then no longer be in the original zone where the horizontal component of rock-flowage is retarded against the belt of eclogite formation and deeps. Its lower levels will be stretched and thinned, and the area will subside as the interior geosyncline had previously done....

To determine the velocities of the sub-continental currents under different circumstances is obviously highly desirable. Such rough estimates as I have attempted to make indicate a velocity of the order $5 \mathrm{~cm}$. per year (50 km. per million years) as probable when the excess of temperature above that corresponding to the critical gradient is $10^{\circ} \mathrm{C}$. On this conservative estimate the minimum period required to produce the Atlantic by continental drift would be some 100 million years.

With ascending currents of such relatively light material, and descending currents made relatively dense by the presence in them of eclogite blocks, the whole circulation will be speeded up while continental drift is in progress. Moreover, the first effect of the formation of a new ocean floor will be in the same direction, since the crustal material previously there will be displaced by much hotter basic material. Later, however, the heat transported to the periphery of the continent and beyond will gradually prevent the formation of eclogite, and the zone of deeps will tend to migrate outwards and disappear. The magma representing what would otherwise have become eclogite [p. 584] will escape through the ocean floor in front of the edges of the sunk borderlands. The supply of sinking blocks having ceased, the current will slow down. At the same time the roots of the mountain system near the margin of the land will become the site of an opposing current (beginning as at D in Fig. 4), since there the heat output will have become greater than that of the continental crust behind. Moreover, as the new ocean floor cools, the ascending currents will fade out for lack of thermal sustenance. For a long time conditions will be chaotic, but gradually an entirely new convective system will evolve tending to close up the continents again. The approach of Africa and Europe across the site of the Tethys is the most striking example of this inevitable reversal of circulation brought about by the changing boundary conditions of an earlier system of currents.

\section{V.- SOME GEOLOGICAL CONSEQUENCES CONTINENTAL DRIFT.}

Turning now to the effects of a radial sub-continental system of convection currents as visualised in plan, it is easy to see that each great continental block—such as Laurasia or Gondwanaland as they were at the close of the Palaeozoic_-should tend to break up into smaller blocks. The latter will drift radially outwards, leaving disruptive basins behind and between, and having geosynclines and borderlands in front, represented later by mountain systems and sunk borderlands.

In the case of Gondwanaland the evidence of late Carboniferous glaciation is here accepted as a definite geological proof that such drifting has since taken place. ... [I]n New South Wales, Rhodesia, South-West Africa and India, the glacial beds are all nearly contemporaneous and of probably late Carboniferous rather than early Permian age. . . . [p. 585] The deduction cannot be escaped that South Africa lay near the South Pole and, if verification be required, it is to be found in the distribution of Upper Carboniferous laterites.... 
But, this being granted, we must envisage not only a radially outward drift of each great land mass towards the Pacific and the Tethys, but also a general drift, possibly involving the whole of the crust, with a northerly component on the African side sufficient to carry the South African region from the South Polar circle, and Britain from the tropics, to their present positions. This picture is rather different from Wegener's, but it is believed to be a reasonable statement of the movements that occurred. Here, then, we have a severe test of the convection hypothesis. Can it provide a northerly drift for the African hemisphere?

In Fig. 5 the combined effects of the two types of circulation so far considered are represented for the time at which the movements leading to our present geography began. A quantitative treatment is at present impracticable, but a roughly qualitative assessment is possible on the assumption that the sub-continental circulation becomes stronger than the planetary circulation. In Gondwanaland the chief ascending current would most probably develope [sic] near the Cape Mountains and their continuations. Thus the planetary circulation would be completely reversed beneath Gondwanaland. In Laurasia the chief ascending currents would be along the Appalachian-Caledonian belt, modified in Europe by the eastward divergence of the Hercynian ranges, and the planetary circulation would thereby be strengthened in the north but reversed in the south. The resultant forces (as represented in Fig. 5) would clearly be in the direction of rotating the whole crust towards the north on the land hemisphere and towards the south on the Pacific side. The success of the hypothesis in providing a possible mechanism for this longpuzzling movement goes far to justify its tentative acceptance.

The hypothesis has other significant implications. It indicates that superimposed on the general crustal drift there would be a relative

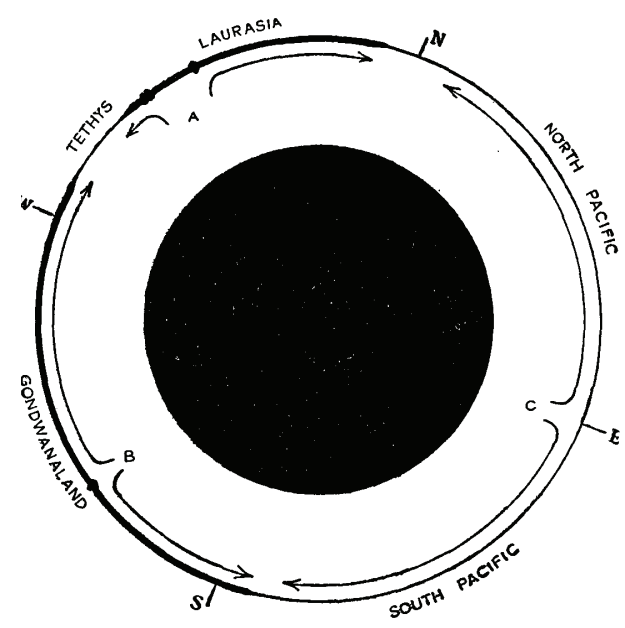

Figure 5.

approach between Africa and Europe. This would be intensified by the resultant of the currents from the hot regions beneath the growing Indian and South Atlantic Oceans. [p. 586] Although these currents would be directed towards the interior of Africa, and would thus place Africa under compression, the resultant would be a drive in a northerly direction. Here we have exactly the conditions postulated by [Émile] Argand and other Alpine geologists as essential to account for the structure of the Alps.

The northerly drift of India would seem incredible if it were not implied by the facts (a) that in the late Carboniferous India was glaciated from the south; (b) that it became an active site of laterite formation from the Eocene onwards; and (c) that the [p. 587] Himalayas and Tibet, from being a depressed marine area have become the highest mountain-flanked plateau on the face of the earth. The very powerful drag that would be necessary to effect the movement and the enormous thickening of the crust to the north implies an unusually vigorous current. The latter can reasonably be referred to the growth of the Indian Ocean, for this would greatly intensify the currents that initiated its formation. As India pushed through the Tethys geosyncline, much of the underlying amphibolite layer would be recrystallised into eclogite and sunk. Only in this way could the great excess of heat that would otherwise have accumulated beneath Tibet have been discharged. Isostatic considerations suggest quite independently that the sial or upper layer of Tibet and the Himalayas must greatly exceed the normal thickness and that the amphibolite layer is likely to be very thin or represented by eclogite. The region is one that may be expected to become the seat of uprising currents that will lead in the future to earth movements and batholithic intrusion on a gigantic scale.

The position of Australia, and the unusual width of the depressed area that separates it from the Australasian arc, are consistent with the assumption that the currents from the Indian Ocean substratum were particularly vigorous. Australasia had not to meet the full resistance-thermal as well as mechanical_of a continental block like Asia, and so, as we find, it travelled even further away from its original site than India did.

Antarctica, on the other hand, was moved in the face of the southward currents of the South Pacific substratum and therefore was unable to drift so far away from the neighbourhood of Africa. Originally it probably lay on the Pacific side of the South Pole, but the general crustal drift already described (Fig. 5) carried it polewards.

No ocean has yet formed between Asia and Europe, although, as Argand has pointed out, the region from the Caspian and Aral Seas to the Obi basin is a relatively depressed one. Presumably the tendency to powerful currents was slight, corresponding to the fact that the Asiatic coast lands are in a much less advanced stage than those of North America. Moreover, the bodily thrusting of the northward extension of India beneath the Tibetan area may have created a thermal resistance which would prevent the normal development of currents beginning to move outwards from the Khirgiz Steppes.

[In the remainder of his paper Holmes endeavoured to show how his hypotheses could account for the formation of peripheral mountain systems, geosynclines, 'median areas' (i.e. little-deformed areas between the two marginal chains; or undeformed areas between deformed belts of similar age), rift valleys, and changes in the relative levels of land and sea.]

\section{[p. 600] VII.- CONCLUSION}

It is not to be expected that the first presentation of a far-reaching hypothesis and its manifold applications can be wholly free from errors. . . . Nevertheless, the preliminary survey that has here been given seems to show that the convection-current hypothesis goes far to account for

(a) the leading features of continental drift since the close of the Palaeozoic;

(b) mountain building and island festoons; 
(c) oceanic deeps;

(d) the initiation and development of geosynclines of various types under both compression and tension;

(e) the growth and disappearance of borderlands;

(f) the varied characters of median areas;

(g) rift valleys;

(h) the distribution of earthquakes;

(i) igneous activity and the distribution of volcanoes;

(j) marine transgressions and recessions; and

( $k$ ) possibly the maintenance of the earth's magnetism.

So far the treatment has been almost entirely qualitative and therefore it inevitably stands in need of criticism and quantitative revision.... Meanwhile its general geological success seems to justify its tentative adoption as a working hypothesis of unusual promise.

\section{Discussion}

Holmes was not the first to seek to provide a general 'theory of the Earth' in terms of convection currents. The Reverend Osmond Fisher's Physics of the Earth's Crust (1881), a book heavy in mathematics written by a mathematician and significant amateur geologist, discussed the idea at some length, but it was written from the perspective of the 1880s in terms of a cooling and contracting Earth. It did not have the diagrams of convection currents such as formed part of Holmes' paper, nor did Fisher have Holmes' vast knowledge of world geology to provide examples to back up his theory (though he provided some). Also, drift theory was not a 'hot topic' in Fisher's time. But it should be noted that he had the hypothetical convection currents rising under the oceans, not the continents.

Holmes' remarkable paper appeared in the context of discussions about the Earth's heat balance and drift theory. It was, then, the first full-scale effort to give a theoretical explanation of Wegener's theory of continental drift in terms of the convective movements of plastic or fluid materials within the Earth. Moreover, it was bold (or rash?) enough to seek to represent what might be going on inside the Earth diagrammatically. His two main figures were reproduced with some modifications in his publications towards the end of his career, in the two editions of his Principles of Physical Geology, as shown here in the figures on the right.

The lower picture (published 1965) reproduces, but also makes clearer, Holmes' earlier ideas about his theory and the caption gives a more lucid idea of his doctrine than that provided in the 1929 paper. Though the 1929 figure has evidently been redrafted and clarified, in the caption to his 1965 publication Holmes is indicating that his ideas about the lateral extent of basaltic oceanic crust have changed since the first publication of the paper. The mysterious "Island or "Swell"" of the older picture is now revealed as representing places like Iceland (not mentioned in the 1929 paper), or perhaps the Azores, though it is unclear why they might be thought to contain continental-type rocks. In the upper picture (1944), Holmes shows 'mixed blocks' consisting of both oceanic and continental material, but it is unclear from the figure what kind of material they were supposedly contained in. If we suppose that the 'New Ocean' is exemplified by the Atlantic then we do indeed have an ocean created by convection currents, and there is an association of mountain ranges such as those of the western parts of the Americas with ocean deeps, as contemplated in modern tectonic theory. Also, the formation of plateau basalts is modelled. However, the theory is, overall, unsatisfactory, despite Holmes' strenuous efforts to demonstrate its considerable explanatory power by application to crustal structures in many parts of the world.

Given the complexities of Holmes' 1929 argument and its failure to deal adequately with many problems it is unsurprising that it was not embraced by many. (Indeed, I was once informed by one of Holmes' former professorial colleagues at Newcastle-upon-Tyne, the late Sergei Tomkeieff, that the theory was thought to be wrong by most of his contemporaries and was ridiculed by some, with students likening his upward-moving convection currents to the froth rising

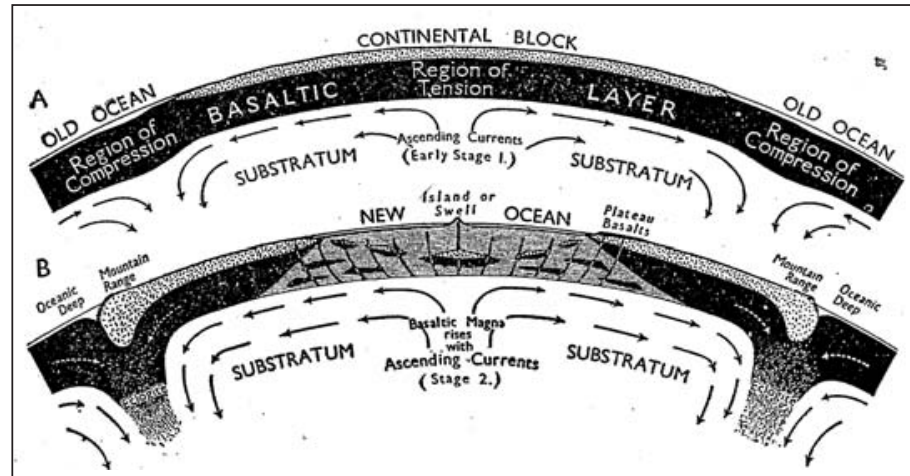

Diagrams to illustrate a purely hypothetical mechanism for "engineering" continental drift. In A sub-crustal currents are in the early part of the convection cycle (Stage 1 of Fig. 215). In B the currents have become sufficiently vigorous (Stage 2 of Fig. 215) to drag the two halves of the original continent apart, with consequent mountain building in front where the currents are descending, and ocean floor development on the site of the gap, where the currents are ascending.

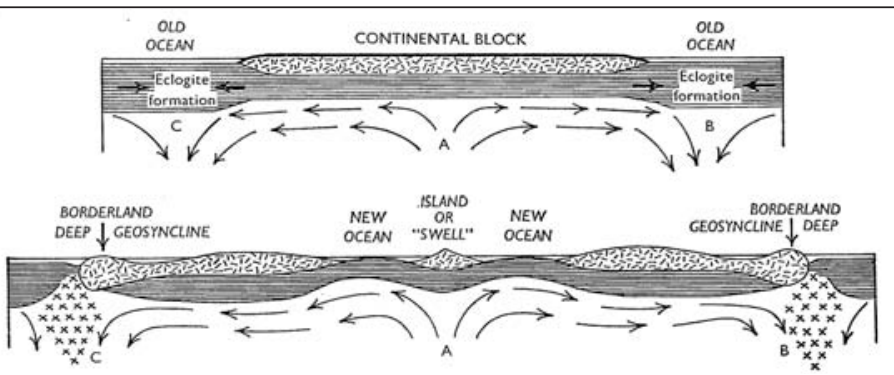

Diagrams to illustrate a convective-current mechanism for "engineering" continental drift and the development of new ocean basins, proposed by the author in 1928, when it was thought that the oceanic crust was a thick continuation of the continental basaltic layer (horizontal line shading).

(a) A current ascending at A spreads out laterally, extends the continental block and drags the two main parts aside, provided that obstruction of the old ocean floor can be overcome. This is accomplished by the formation of eclogite at $\mathrm{B}$ and $\mathrm{C}$, where sub-continental currents meet sub-oceanic currents and turn downwards. Being heavy, eclogite is carried down, so making room for the continents to advance.

(b) the foundering masses of eclogite at $\mathrm{B}$ and $\mathrm{C}$ share in the main covective circulation and, melting at depth to form basaltic magma, the material rises in ascending currents: e.g. at A, healings the gaps in the disrupted continent and forming new ocean floors (locally with a swell of old sial left behind, such as Iceland). Other smaller current systems, set going by the buoyancy of basaltic magma, ascend beneath the continents and feed great floods of plateau basalts, or beneath the 'old' (Pacific) ocean floor to feed the outpourings responsible for the volcanic islands and seamounts (Arthur Holmes, Transactions of the Geological Society of Glasgow, 1928-1929, vol.18, p. 579)

Representations of Holmes' theory from his Principles of Physical Geology, 1st edn, 1944, p. 506 (top); 2nd edn, 1965, p. 1001 (bottom). 
in a glass of beer!) However, its original purpose, like that of Joly's theory, was to provide a mechanism for the escape of radiogenic heat; and the idea that continental masses might be moved by underlying convection currents offered a successful way forward on this problem. Of course, Holmes was not familiar with the topographies of the oceanic floors (apart from the 'deeps' investigated by Vening Meinesz) and so, not knowing about the emission of magma at mid-oceanic ridges, he had his convection currents rising in the 'wrong places'. But his misapprehension was understandable. One might reasonably expect the 'uplift' from rising convection currents to occur under the Earth's elevated regions, not the ocean floors. And Holmes' personal geological experience was to a considerable extent based on his years in East Africa, where uplift, volcanism and rifting are all found. Moreover, at the time when he proposed his convection theory contraction was still seen as the dominant force in global tectonics and Wegener-type theories were making little headway.

\section{References}

Bull, A. J. 1921. A hypothesis of mountain building: Geological Magazine, v. 52, pp. 364-367.

Fisher, O. 1889. Physics of the Earth's Crust: London and New York, Macmillan and Co. (2nd edn).

Frankel, H. 1978. Arthur Holmes and continental drift: The British Journal for the History of Science, v. 11, pp. 130-150.

Fritscher, B. 2002. Alfred Wegener's "The Origin of Continents", 1912: Episodes, v. 25, pp. 100-106.

Holmes, A. 1925a. Radioactivity and the Earth's thermal history. Part IV: A criticism of Parts I, II, and III: Geological Magazine, v. 62, pp. 504-515.

Holmes, A. 1925b. Radioactivity and the Earth's thermal history. Part $\mathrm{V}$ : The control of geological history by radioactivity: Geological Magazine, v. 62, pp. 529-544.
Holmes, A. 1927. Oceanic deeps and the thickness of the continents: Nature, v. 120, pp. 804-805.

Holmes, A. 1928. Radioactivity and continental drift: Geological Magazine, v. 65, pp. 236-238.

Holmes, A. 1929. Radioactivity and earth movements: Transactions of the Geological Society of Glasgow, v. 18 (Part 3), pp. 559606.

Holmes, A. 1944. Principles of Physical Geology: London, Edinburgh, Paris, Melbourne, Toronto and New York, Thomas Nelson and Sons Ltd. 2nd edn 1965.

Jeffreys, H. 1929. The Earth: Its Origin, History and Physical Constitution: Cambridge, Cambridge University Press, 2nd edn.

Joly, J. 1910. Radioactivity and Geology: An Account of the Influence of Radioactive Energy on Terrestrial History: London, Archibald Constable \& Co. Ltd.

Joly, J. 1924. Radioactivity and the Surface History of the Earth being the Halley Lecture delivered on 28 May, 1924: Oxford: Clarendon Press.

Joly, J. 1925. The Surface-History of the Earth: Oxford, Clarendon Press.

Lewis, C. 2000. The Dating Game: One Man's Search for the Age of the Earth: Cambridge, New York, Oakleigh, Madrid and Cape Town, Cambridge University Press.

Oldham, R. D. 1906. The constitution of the Earth as revealed by earthquakes: Quarterly Journal of the Geological Society of London, v. 62, pp. 456-475.

Van Waterschoot van der Gracht, W. A. J. M. (ed.). 1928. The Theory of Continental Drift: A Symposium: London, John Murray.

Vening Meinesz, F. A. 1930. Maritime gravity survey in the Netherlands East Indies, tentative interpretation of the provisional results: Proceedings of the Koninklijke Nederlandse Akademie van Wetenschappen te Amsterdam, Proccedings, v. 33, pp. 566577.

Wegener, A. 1915. Die Entstehung der Kontinente und Ozeane: Braunschweig, Vieweg. 